\title{
Introducing Chiral Bifunctional Phosphine-Carboxylate Ligands for Palladium(0)-Catalyzed Enantioselective C-H Arylation
}

\author{
Lei Yang, Markus Neuburger, and Olivier Baudoin*
}

\begin{abstract}
Previous enantioselective $P d^{0}$-catalyzed $\mathrm{C}-\mathrm{H}$ activation reactions proceeding via the concerted metalation-deprotonation mechanism employed either a chiral ancillary ligand, a chiral base, or a bimolecular mixture thereof. This study describes the development of new chiral bifunctional ligands based on a binaphthyl scaffold and incorporating both a phosphine and a carboxylic acid moiety. The optimal ligand provided high yields and enantioselectivities for the desymmetrizing $C\left(s p^{2}\right)-H$ arylation leading to 5,6-dihydrophenanthridines, whereas the corresponding monofunctional ligands showed low enantioselectivities. The bifunctional system proved applicable to a range of substituted dihydrophenanthridines, and allowed the parallel kinetic resolution of racemic substrates.
\end{abstract}

In recent years, catalytic enantioselective $\mathrm{C}-\mathrm{H}$ activation has emerged as a simple and powerful method to construct different types of stereogenic elements (central, planar or axial) and generate high value-added enantioenriched molecules. ${ }^{[1]}$ In the context of palladium(0)-catalyzed $\mathrm{C}-\mathrm{H}$ activation/ $\mathrm{C}-\mathrm{C}$ coupling reactions proceeding via the catalytic cycle depicted in Scheme 1a, the enantiodetermining step is usually the $\mathrm{C}-\mathrm{H}$ activation, which occurs via the concerted metalation-deprotonation (CMD, aka AMLA) mechanism. ${ }^{[2]}$ According to the latter, the substrate, an ancillary ligand $(\mathrm{L})$ and the base performing the $\mathrm{C}-\mathrm{H}$ bond cleavage $\left(\mathrm{RYO}_{2}{ }^{-}\right)$ are all coordinated to the palladium center at the transition state. Consistent with this mechanism, two types of chiral catalysts have been successfully employed to induce enantioselectivity in $\mathrm{Pd}^{0}$ catalyzed $\mathrm{C}\left(\mathrm{sp}^{2}\right)-\mathrm{H}$ and $\mathrm{C}\left(\mathrm{sp}^{3}\right)-\mathrm{H}$ activation reactions (Scheme $1 \mathrm{~b}$ ): 1. chiral ancillary ligands, more specifically phosphorus(III) compounds $s^{[3,4]}$ and $\mathrm{NHCs}^{[5]}$ and 2 . chiral bases, e. g. carboxylates $^{[4 a, b]}$ and Binol-derived phosphates. ${ }^{[6]}$ The union of an ancillary ligand and base in the same bifunctional molecule has not been achieved so far in the context of $\mathrm{Pd}^{0}$-catalyzed enantioselective $\mathrm{C}-\mathrm{H}$ activation, ${ }^{[7]}$ and is the subject of the current work (Scheme 1c). Such a bifunctional ligand would possess a more organized structure compared to the corresponding bimolecular system, and might be broadly applicable to various types of asymmetric $\mathrm{C}-\mathrm{H}$ activation reactions operating via a similar mechanism

At the onset of our work, we chose to focus on phosphinecarboxylate bifunctional ligands based on the classic binaphthalene

[*] Dr. L. Yang, Dr. M. Neuburger, Prof. Dr. O. Baudoin University of Basel, Department of Chemistry, St. Johanns-Ring 19, CH-4056 Basel, Switzerland

E-mail: olivier.baudoin@unibas.ch

Dr. L. Yang

State Key Laboratory for Oxo Synthesis and Selective Oxidation, Lanzhou Institute of Chemical Physics (LICP), Chinese Academy of Sciences, Lanzhou 730000, P.R. China

Supporting information for this article is available on the WWW under http://www.angewandte.org or from the author.

a) general mechanism of $\mathrm{Pd}^{0}$-catalyzed $\mathrm{C}-\mathrm{H}$ activation/C-C coupling:

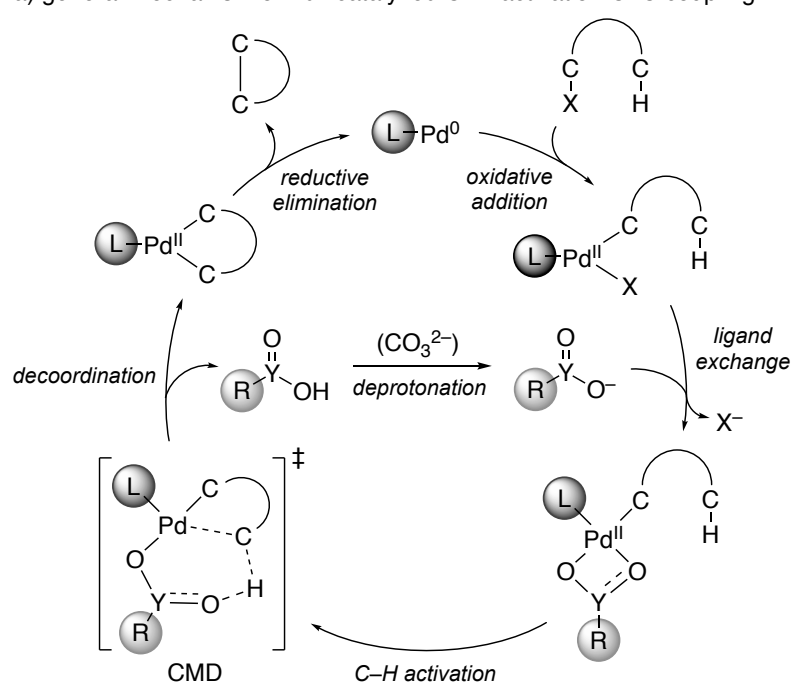

b) known chiral catalysts inducing enantioselectivity:

L chiral ancillary ligand: phosphine, phosphoramidite, phosphonite, $\mathrm{N}$-heterocyclic carbene...

$\mathrm{R}^{-} \mathrm{Y}_{\mathrm{O}^{-}}$chiral base: carboxylate $(\mathrm{Y}=\mathrm{C})$, phosphate $(\mathrm{Y}=\mathrm{P})$

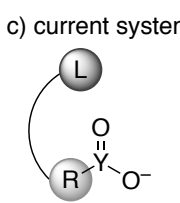

chiral bifunctional ligand phosphine/carboxylate

Scheme 1. State-of-the-art and current chiral catalysts for $\mathrm{Pd}^{0}$ catalyzed $\mathrm{C}-\mathrm{H}$ arylation.

scaffold (Schemes 1c, 2). A series of phosphine-carboxylic acid preligands $\mathbf{L}^{3}-\mathbf{L}^{7}$ with a variable number (1-5) of methylene groups separating the carboxylic acid and the binaphthyl core were prepared from $(R)$-Binol by adapting literature procedures from Uozumi, Hayashi and co-workers (Scheme 2). ${ }^{[8,9]}$ As a prototypical reaction, we chose to investigate the enantioselective $\mathrm{C}-\mathrm{H}$ arylation of aryl bromide 1a to give 5,6-dihydrophenanthridine 2a. This structural motif is present in various biologically active substances, in particular fluorogenic probes for the detection of reactive oxygen species. ${ }^{[10]}$ Related $\mathrm{Pd}^{0}$-catalyzed desymmetrizing $\mathrm{C}\left(\mathrm{sp}^{2}\right)-\mathrm{H}$ arylations generating carbon, ${ }^{[3 a, c]}$ phosphorus ${ }^{[11]}$ or silicon $^{[3 b, h]}$ stereocenters have been reported using a chiral phosphorus ligand and an achiral base, but such an enantioselective synthesis of 5,6dihydrophenanthridines has not been described. ${ }^{[12,13]}$ 


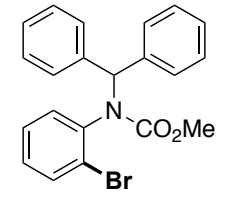

$1 \mathrm{a}$

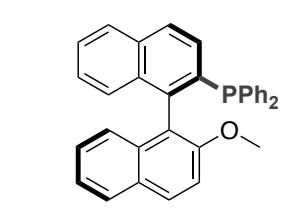

$\mathrm{L}^{1}$ (MOP)

$78 \%$, e.r. $51: 49$

$+\mathrm{PivOH}:[\mathrm{b}] 96 \%$, e.r. $63.5: 36.5$

$+\mathrm{AcOH}:[\mathrm{b}] 85 \%$, e.r. $57: 43$

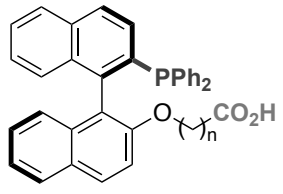

$L^{3} \mathrm{n}=1: 91 \%$, e.r. $93.5: 6.5$

$\mathrm{L}^{4} \mathrm{n}=2: 95 \%$, e.r. $75: 25$

$L^{5} \mathrm{n}=3: 95 \%$, e.r. $80.5: 19.5$

$\mathrm{L}^{6} \mathrm{n}=4: 90 \%$, e.r. $48: 52$

$L^{7} n=5: 83 \%$, e.r. $46: 54$

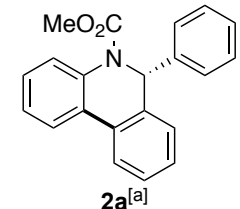

$2 \mathrm{a}^{[\mathrm{a}]}$

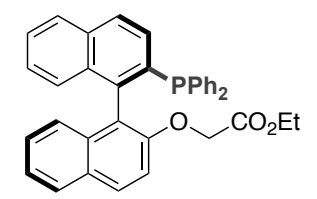

$\mathbf{L}^{2}$

$+\mathrm{PivOH}:[\mathrm{b}] 87 \%$, e.r. $58.5: 41.5$

$+\mathrm{AcOH}:{ }^{[\mathrm{b}]} 95 \%$, e.r. $54: 46$

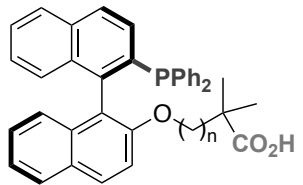

$L^{8} \mathrm{n}=0: 95 \%$, e.r. $81: 19$

$L^{9} n=2: 85 \%$, e.r. $79.5: 20.5$

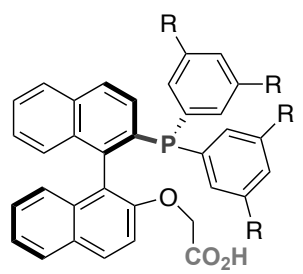

$L^{10} R=$ Me: $92 \%$, e.r. $97.5: 2.5$

$L^{11} \mathrm{R}=$ OMe: $96 \%$, e.r. $97: 3$

$\mathrm{L}^{12} \mathrm{R}=t$-Bu: $94 \%$, e.r. $91: 9$

$\mathrm{L}^{13} \mathrm{R}=\mathrm{CF}_{3}: 87 \%$, e.r. $89: 11$
Scheme 2. Synthesized bifunctional ligands and their effect in enantioselective $\mathrm{C}\left(\mathrm{sp}^{2}\right)-\mathrm{H}$ arylation. [a] The absolute configuration of 2a was deduced from the Xray crystal structure shown in Scheme 3. [b] $15 \mathrm{~mol} \%$.

Standard reaction conditions involved the combination of the ligand $(10 \mathrm{~mol} \%)$ with $\mathrm{Pd}_{2} \mathrm{dba}_{3}$ as a carboxylate-free Pd source $(5$ mol\% Pd), stoichiometric cesium carbonate, which is able to both deprotonate the carboxylic acid function of the ligand to generate the active carboxylate in situ and regenerate it after the $\mathrm{C}-\mathrm{H}$ activation step (see Scheme 1a), and DME as the solvent at $120{ }^{\circ} \mathrm{C}$ in the presence of molecular sieves to remove traces of potentially deleterious water molecules. ${ }^{[6 b]}$ The enantioselectivity obtained with bifunctional ligands was compared to the one obtained with the corresponding monofunctional ligands $\mathbf{L}^{\mathbf{1}}(\mathrm{MOP})^{[14]}$ and $\mathbf{L}^{\mathbf{2}}$ containing an ethyl ester instead of the carboxylic acid. All bifunctional ligands $\mathbf{L}^{3}-\mathbf{L}^{7}$ enabled the reaction in very good yield, but with various levels of enantioselectivities, showing the effect of the carbon spacer length (Scheme 2). The enantioselectivity was maximal for MOP-acetic acid hybrid ligand $\mathbf{L}^{3}$ containing one methylene spacer, which furnished 5,6-dihydrophenanthridine $\mathbf{2 a}$ in 91\% yield and 93.5:6.5 e.r.. Importantly, the enantioselectivity was much lower in control experiments performed with monofunctional ligands $\mathbf{L}^{\mathbf{1}}$ and $\mathbf{L}^{\mathbf{2}}$ both in the absence and in the presence of pivalic or acetic acid additive. Moreover, although the enantioselectivity was low with ligands $\mathbf{L}^{6}-\mathbf{L}^{7}$ bearing a longer carbon spacer, the sense of the induction was inverted compared to $\mathbf{L}^{1}-\mathbf{L}^{2}$. All together, these results strongly indicate that ligands $\mathbf{L}^{3}-\mathbf{L}^{7}$ operate in a bifunctional mode. In addition, the most selective ligand $\mathbf{L}^{3}$ provided a much higher enantioselectivity than comparable bimolecular systems composed of $\mathbf{L}^{\mathbf{1}}$ or $\mathbf{L}^{\mathbf{2}}$ and $\mathrm{AcOH}$ or PivOH. Of note, we also tested other chiral ligands such as BINAP, TADDOLderived phosphoramidites, and NHCs, which were previously employed in asymmetric $\mathrm{Pd}^{0}$-catalyzed $\mathrm{C}-\mathrm{H}$ activation reactions, ${ }^{[3-4]}$ but they provided lower enantioselectivities than $\mathbf{L}^{3} \cdot{ }^{[9]}$

In search for a further improvement of the enantioselectivity, we first synthesized MOP-pivalic acid hybrids $\mathbf{L}^{\mathbf{8}}$ and $\mathbf{L}^{\mathbf{9}}$, but the enantioselectivity was reduced compared to ligands $\mathbf{L}^{3}$ and $\mathbf{L}^{5}$ deprived of gem-dimethyl groups. The modification of aryl substituents on the phosphorus atom turned out to be more successful $\left(\mathbf{L}^{\mathbf{1 0}}-\mathbf{L}^{\mathbf{1 3}}\right)$, with dimethyl and dimethoxy-substituted ligands $\mathbf{L}^{\mathbf{1 0}}-\mathbf{L}^{\mathbf{1 1}}$ affording the highest enantiomeric ratio. Further refinement of reaction conditions was performed using $\mathbf{L}^{\mathbf{1 0}}$, including other carbonate bases, solvents and temperatures. ${ }^{[9]}$ These studies allowed to decrease the amount of $\mathrm{Cs}_{2} \mathrm{CO}_{3}$ to 1.5 equiv and the temperature to $80{ }^{\circ} \mathrm{C}$, and to achieve an e.r. of $98.5: 1.5$ with a $92 \%$ yield on a 1 mmol (fivefold) scale (Scheme 3a). Importantly, a control experiment performed with 1 equiv of the potassium salt derived from $\mathbf{L}^{\mathbf{1 0}}$ and in the absence of cesium carbonate still furnished product $\mathbf{2 a}$ in $92 \%$ yield and a slightly reduced e.r. of 95.5:4.5. ${ }^{[9]}$ This experiment further supports our hypothesis that this ligand is not a mere bidentate ligand, but it also acts as the base participating in the CMD mechanism (Scheme 1c). In this case the main role of the stoichiometric carbonate is to regenerate the active carboxylate ligand after the $\mathrm{C}-\mathrm{H}$ activation step.

Employing these optimal conditions, we studied the scope and limitations of the catalytic enantioselective synthesis of 5,6dihydrophenanthridines catalyzed by $\mathrm{Pd} / \mathbf{L}^{\mathbf{1 0}}$ (Scheme 3 ). For less reactive substrates, the reaction was performed at higher temperatures as indicated. First, the optimal leaving group was found to be a bromide (Scheme 3a). Lower yields of 2a were obtained from the corresponding iodide and chloride, whereas the triflate underwent decomposition and no desired product was observed. Next, we studied the impact of the nitrogen substituent on the reaction (Scheme $3 b$ ). The best results were obtained with alkoxycarbonyl groups (2a-c). With a tosyl group (2d), a diminished enantioselectivity was observed, whereas with methyl (2e) and trifluoroacetyl (2f) groups the reaction was sluggish and gave several decomposition products. With bromide as the leaving group and methoxycarbonyl as the $N$-substituent, different types of $\mathrm{R}^{1}$ groups were introduced on the bromine-containing aromatic ring, with equally excellent yields and enantioselectivities (Scheme 3c, 2g-m). Of note, the X-ray diffraction analysis of a single crystal of $\mathbf{2 k}$ allowed determination of its absolute configuration as $(R) \cdot{ }^{[15]} \mathrm{In}$ addition, substrates containing a naphthalene (2n) or a pyridine (2o) ring performed with similar efficiency and enantioselectivity. Similarly, the reaction was compatible with $\mathrm{R}^{2}$ substituents at various positions of the other aryl rings (Scheme $3 \mathrm{~d}, \mathbf{2 p - v}$ ). In the case of $\mathbf{2 s}$, the $\mathrm{C}-\mathrm{H}$ arylation occurred selectively at the most reactive ortho position to the fluorine atom, ${ }^{[16]}$ as shown by ${ }^{1} \mathrm{H}-{ }^{19} \mathrm{~F}$ HOESY ${ }^{\left[{ }^{[9]}\right.}$ On the other hand, a limitation was found when the connection of the rings undergoing $\mathrm{C}-\mathrm{C}$ coupling was changed (Scheme 3e). A drop in the yield and the enantioselectivity was indeed observed for compounds $2 \mathbf{w}-\mathbf{y}$ containing a different 6- or 7membered bridging ring. Achieving efficient enantioselective syntheses of these motifs would likely require further optimization of the ligand structure. For instance, using $t$-Bu-substituted ligand $\mathbf{L}^{12}$ instead of $\mathbf{L}^{10}$ significantly improved the enantioselectivity in the formation of sultam $\mathbf{2 y}$. 


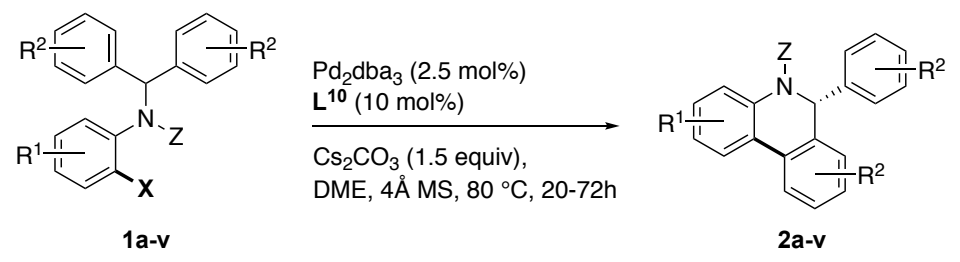

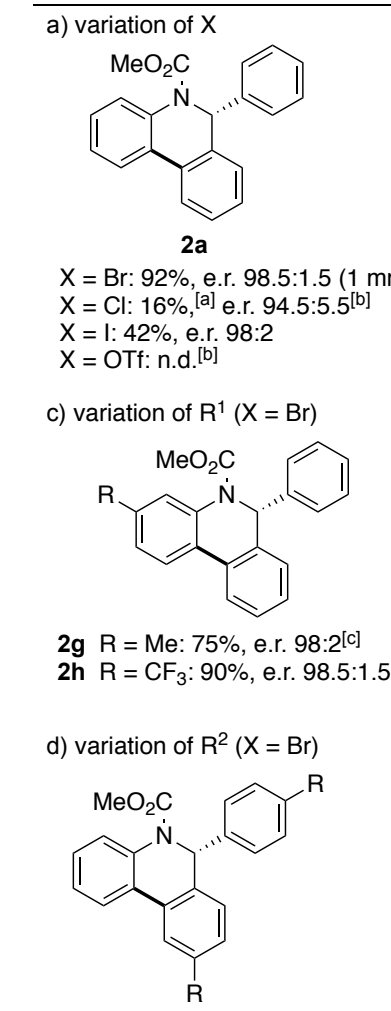

2p $R=$ Me: $80 \%$, e.r. $97.5: 2.5$ 2q $R=F: 93 \%$, e.r. $98.5: 1.5$

2r R = OMe: $78 \%$, e.r. $98.5: 1.5$

e) unsuccessful examples $(X=B r)$<smiles>c1ccc(C2Oc3ccccc3-c3ccccc32)cc1</smiles>

2w $10 \%$, e.r. $58: 42^{[d]}$ b) variation of $Z(X=B r)$<smiles>[Z]N1c2ccccc2-c2ccccc2[C@@H]1c1ccccc1</smiles>

2b Z $=\mathrm{CO}_{2} \mathrm{Et}: 91 \%$, e.r. $98.5: 1.5$

2c $Z=\mathrm{CO}_{2} i$-Bu: $89 \%$, e.r. $98.5: 1.5$

2d $Z=$ Ts: $88 \%$, e.r. $93: 7$

2e $Z=$ Me: $44 \%$, e.r. $82.5: 17.5^{[b]}$

2f $\mathrm{Z}=\mathrm{COCF}_{3}$ : traces<smiles>[R]c1ccc2c(c1)-c1ccccc1[C@@H](c1ccccc1)N2C(C)=O</smiles>

2i $R=$ Me: $83 \%$, e.r. $98.5: 1.5$

2j $R=F: 90 \%$, e.r. $98: 2^{[c]}$

2k R $=\mathrm{Cl}$ : $92 \%$, e.r. $96.5: 3.5$

2I $\mathrm{R}=\mathrm{CO}_{2} \mathrm{Me}: 80 \%$, e.r. $98.5: 1.5$<smiles>CC(=O)N1c2ccccc2-c2c(F)cccc2[C@H]1c1cccc(F)c1</smiles>

2s $87 \%$, e.r. $96.5: 3.5$<smiles>CC(=O)N1c2c(C)cc(C)cc2-c2ccccc2[C@H]1c1ccccc1</smiles>

$2 \mathrm{~m} 82 \%$, e.r. $97: 3$<smiles>COC(=O)N1c2ccccc2-c2c(C)cc(C)cc2[C@H]1c1cc(C)cc(C)c1</smiles>

2t $83 \%$, e.r. $96.5: 3.5 \quad 2 u R=M e: 78 \%$, e.r. $88: 12^{[b]}$

2v R $=$ F: $81 \%$, e.r. $95: 5^{[c]}$<smiles>COC(=O)N1c2ccc3ccccc3c2-c2ccccc2[C@H]1c1ccccc1</smiles>

2n $93 \%$, e.r. $98: 2$<smiles>[R]c1ccccc1[C@@H]1c2c([R])cccc2-c2ccccc2N1C(C)=O</smiles>

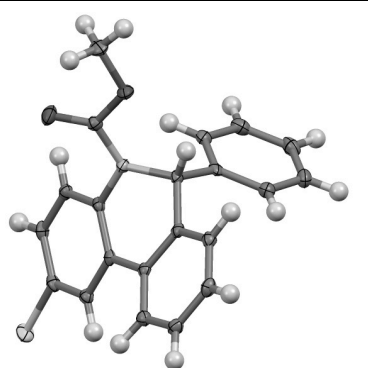

X-ray structure of $\mathbf{2} \mathbf{k}^{[\mathrm{e}]}$<smiles>CC(=O)N1c2cccnc2-c2ccccc2[C@H]1c1ccccc1</smiles>

2 o $73 \%$, e.r. $94: 6$<smiles>CN1C(=O)c2ccccc2-c2ccccc2C1c1ccccc1</smiles>

$2 x$ traces $^{[\mathrm{d}]}$<smiles>CN1C(c2ccccc2)c2ccccc2-c2ccccc2S1(=O)=O</smiles>

2y $76 \%$, e.r. $52: 48^{[\mathrm{d}]}$

$82 \%$, e.r. $67: 33^{[f]}$

Scheme 3. Scope and limitations of the enantioselective synthesis of 5,6-dihydrophenanthridines. [a] NMR yield. [b] Performed at $120{ }^{\circ} \mathrm{C}$. [c] Performed at $100{ }^{\circ} \mathrm{C}$. [d] Performed at $140{ }^{\circ} \mathrm{C}$. [e] Thermal ellipsoids at the $50 \%$ probability level. [f] Using ligand $L^{12}$ instead of $L^{10}$. The absolute configurations of other products were ascribed by analogy to $\mathbf{2 k}$. n.d. = not detected.

Finally, inspired from the work of Kündig ${ }^{[5 b]}$ and more recently Cramer ${ }^{[17]}$ in $\mathrm{C}\left(\mathrm{sp}^{3}\right)-\mathrm{H}$ and $\mathrm{C}\left(\mathrm{sp}^{2}\right)-\mathrm{H}$ arylation, we examined the parallel kinetic resolution (PKR) of racemic substrates 3-4 (Scheme 4). This behavior is based on the fact that differently substituted aryl groups undergo $\mathrm{C}-\mathrm{H}$ arylation at similar rates. Since a given enantiomer of the chiral catalyst always selects the same enantiotopic aryl group, two enantioenriched constitutional isomers with the same absolute configuration can be obtained with a maximum of $50 \%$ yield each. Indeed, reacting 3 and $\mathbf{4}$ under standard conditions led to $c a$. 1:1 mixtures of highly enantioenriched isomers $\mathbf{5 a} / \mathbf{5 b}$ and $\mathbf{6 a / 6}$ in excellent combined yields. This result is in line with previous reports, ${ }^{[5 b, 17]}$ hence tending to indicate the general character of $\mathrm{PKR}$ via $\mathrm{Pd}^{0}$-catalyzed $\mathrm{C}-\mathrm{H}$ activation.

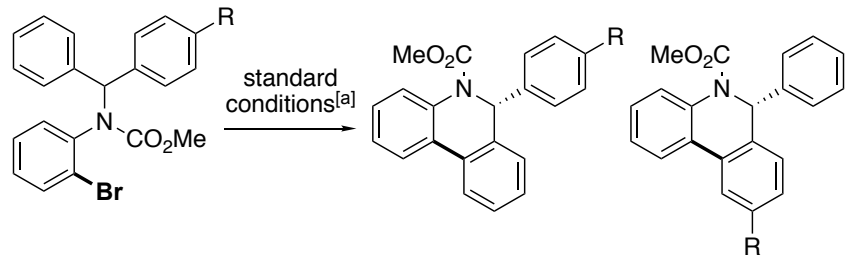
(土)-3 $R=F$
$( \pm)-4 \mathrm{R}=\mathrm{Me}$
5a $\mathrm{R}=\mathrm{F}$
5b $R=F$
5a/5b 1:1, 87\%, ${ }^{[b]}$ e.r 99:1 \& 97.5:2.5
6a/6b 1:1, 85\%, ${ }^{[b]}$ e.r 98.5:1.5 \& $98: 2$

Scheme 4. Parallel kinetic resolution of racemic substrates. [a] $\mathrm{Pd}_{2} \mathrm{dba}_{3}$ (2.5 mol\%), L ${ }^{10}$ (10 mol\%), $\mathrm{Cs}_{2} \mathrm{CO}_{3}$ (1.5 equiv), DME, 4A MS, $80{ }^{\circ} \mathrm{C}$. [b] Combined yield of the isolated mixture of inseparable isomers. 
In conclusion, chiral bifunctional phosphine/carboxylate ligands based on a binaphthyl scaffold showed high efficiency and enantioselectivity for the desymmetrizing $\mathrm{C}\left(\mathrm{sp}^{2}\right)-\mathrm{H}$ arylation leading to 5,6-dihydrophenanthridines. In contrast, the corresponding monofunctional ligands deprived of carboxylic acid function induced only low enantioselectivities, thereby demonstrating the added value of bifunctionality. This new ligand type might show broad applicability to various types of asymmetric $\mathrm{C}-\mathrm{H}$ activation reactions operating via the CMD mechanism.

\section{Acknowledgements}

This work was financially supported by the People Programme (Marie Curie Actions) of the European Union's Seventh Framework Programme FP7/2007-2013/ under REA grant agreement no. 623605, and by the University of Basel. We thank Dr. D. Häussinger for NMR experiments, S. Mittelheisser and Dr. H. Nadig for MS analyses. L. Y. acknowledges the support from the National Natural Science Foundation of China (Grant No. 21372231).

\section{Conflict of interest}

The authors declare no conflict of interest.

Received: ((will be filled in by the editorial staff))

Published online on ((will be filled in by the editorial staff))

Keywords: arylation - asymmetric catalysis - $\mathrm{C}-\mathrm{H}$ activation palladium $\cdot P$ ligands

[1] C. G. Newton, S.-G. Wang, C. C. Oliveira, N. Cramer, Chem. Rev. 2017, 117,8908

[2] a) L. Ackermann, Chem. Rev. 2011, 111, 1315; b) D. L. Davies, S. A. Macgregor, C. L. McMullin, Chem. Rev. 2017, 117, 8649.

[3] Selected examples in $\mathrm{C}\left(\mathrm{sp}^{2}\right)-\mathrm{H}$ activation: a) M. R. Albicker, N. Cramer, Angew. Chem. Int. Ed. 2009, 48, 9139; b) R. Shintani, H. Otomo, K. Ota, T. Hayashi, J. Am. Chem. Soc. 2012, 134, 7305; c) T. Saget, N. Cramer, Angew. Chem. Int. Ed. 2013, 52, 7865; d) R. Deng, Y. Huang, X. Ma, G. Li, R. Zhu, B. Wang, Y.-B. Kang, Z. Gu, J. Am. Chem. Soc. 2014, 136, 4472; e) D.-W. Gao, Q. Yin, Q. Gu, S.-L. You, J. Am. Chem. Soc. 2014, 136, 4841; f) Z.-Q. Lin, W.-Z. Wang, S.-B. Yan, W.-L. Duan, Angew. Chem. Int. Ed. 2015, 54, 6265; g) L. Liu, A.-A. Zhang, Y. Wang, F. Zhang, Z. Zuo, W.-X. Zhao, C.-L. Feng, W. Ma, Org. Lett. 2015, 17, 2046; h) J. Wang, D.-W. Gao, J. Huang, S. Tang, Z. Xiong, H. Hu, S.-L. You, ACS Catal. 2017, 7, 3832; i) Y.
Sato, C. Takagi, R. Shintani, K. Nozaki, Angew. Chem. Int. Ed. 2017, 56, 9211; j) C. He, M. Hou, Z. Zhu, Z. Gu, ACS Catal. 2017, 7, 5316.

[4] Selected examples in $\mathrm{C}\left(\mathrm{sp}^{3}\right)-\mathrm{H}$ activation: a) S. Anas, A. Cordi, H. B. Kagan, Chem. Commun. 2011, 47, 11483; b) T. Saget, S. J. Lemouzy, N. Cramer, Angew. Chem. Int. Ed. 2012, 51, 2238; c) N. Martin, C. Pierre, M. Davi, R. Jazzar, O. Baudoin, Chem. Eur. J. 2012, 18, 4480; d) T. Saget, N. Cramer, Angew. Chem. Int. Ed. 2012, 51, 12842; e) J. Pedroni, M. Boghi, T. Saget, N. Cramer, Angew. Chem. Int. Ed. 2014 53, 9064; f) P. M. Holstein, M. Vogler, P. Larini, G. Pilet, E. Clot, O. Baudoin, ACS Catal. 2015, 5, 4300; g) J. Pedroni, N. Cramer, Angew. Chem. Int. Ed. 2015, 54, 11826; h) C. L. Ladd, A. B. Charette, Org. Lett. 2016, 18, 6046; i) D. Dailler, R. Rocaboy, O. Baudoin, Angew. Chem. Int. Ed. 2017, 56, 7218.

[5] a) M. Nakanishi, D. Katayev, C. Besnard, E. P. Kündig, Angew. Chem. Int. Ed. 2011, 50, 7438; b) D. Katayev, M. Nakanishi, T. Bürgi, E. P. Kündig, Chem. Sci. 2012, 3, 1422; c) E. Larionov, M. Nakanishi, D. Katayev, C. Besnard, E. P. Kündig, Chem. Sci. 2013, 4, 1995.

[6] a) S. Zhang, J. Lu, J. Ye, W.-L. Duan, Chin. J. Org. Chem. 2016, 36, 752; b) L. Yang, R. Melot, M. Neuburger, O. Baudoin, Chem. Sci. 2017, 8, 1344.

[7] Selected references on the use of bifunctional ligands in $\mathrm{Pd}^{\mathrm{II}}$-catalyzed enantioselective C-H activation: a) B.-F. Shi, N. Maugel, Y.-H. Zhang, J.-Q. Yu, Angew. Chem. Int. Ed. 2008, 47, 4882; b) K. M. Engle, J.-Q. Yu, J. Org. Chem. 2013, 78, 8927; c) G. Chen, W. Gong, Z. Zhuang, M. S. Andrä, Y.-Q. Chen, X. Hong, Y.-F. Yang, T. Liu, K. N. Houk, J.-Q. Yu, Science 2016, 353, 1023; d) B. E. Haines, J.-Q. Yu, D. G. Musaev, ACS Catal. 2017, 7, 4344; e) Y.-F. Yang, G. Chen, X. Hong, J.-Q. Yu, K. N. Houk, J. Am. Chem. Soc. 2017, 139, 8514.

[8] Compounds $\mathbf{L}^{2}-\mathbf{L}^{3}$ and $\mathbf{L}^{5}-\mathbf{L}^{7}$ have been previously synthesized, but only used as intermediates for the synthesis of supported MOP ligands: a) Y. Uozumi, H. Danjo, T. Hayashi, Tetrahedron Lett. 1998, 39, 8303; b) H. Hocke, Y. Uozumi, Tetrahedron 2004, 60, 9297; c) Y. Uozumi, T. Hayashi, Jpn. Kokai Tokkyo Koho, JP11147890, 1999.

[9] See the Supporting Information for details.

[10] K. Debowska, D. Debski, M. Hardy, M. Jakubowska, B. Kalyanaraman, A. Marcinek, R. Michalski, B. Michalowski, O. Ouari, A. Sikora, R. Smulik, J. Zielonka, Pharmacol. Rep. 2015, 67, 756.

[11] See refs. 3f,g and: a) G. Xu, M. Li, S. Wang, W. Tang, Org. Chem. Front. 2015, 2, 1342; b) Y. Lin, W.-Y. Ma, Q.-Y. Sun, Y.-M. Cui, L.W. Xu, Synlett 2017, 28, 1432.

[12] For a review of related non-asymmetric reactions: F. Rafiee, Appl. Organometal. Chem. 2017, e3820.

[13] For another $\mathrm{C}-\mathrm{H}$ activation-based enantioselective approach to this motif: K.-J. Xiao, L. Chu, G. Chen, J.-Q. Yu, J. Am. Chem. Soc. 2016, $138,7796$.

[14] T. Hayashi, Acc. Chem. Res. 2000, 33, 354.

[15] CCDC 1581525 (2k) contains the supplementary crystallographic data for this paper. These data can be obtained free of charge from The Cambridge Crystallographic Data Centre via www.ccdc.cam.ac.uk/data_request/cif.

[16] L.-C. Campeau, M. Parisien, A. Jean, K. Fagnou, J. Am. Chem. Soc. 2006, 128,581

[17] a) J. Pedroni, N. Cramer, J. Am. Chem. Soc. 2017, 139, 12398; b) D. Grosheva, N. Cramer, ACS Catal. 2017, 7, 7417. 


\section{C-H Activation}

L. Yang, M. Neuburger, O.

Baudoin*

Page - Page

Introducing Chiral Bifunctional

Phosphine-Carboxylate Ligands for

Palladium(0)-Catalyzed Enantioselective

C-H Arylation

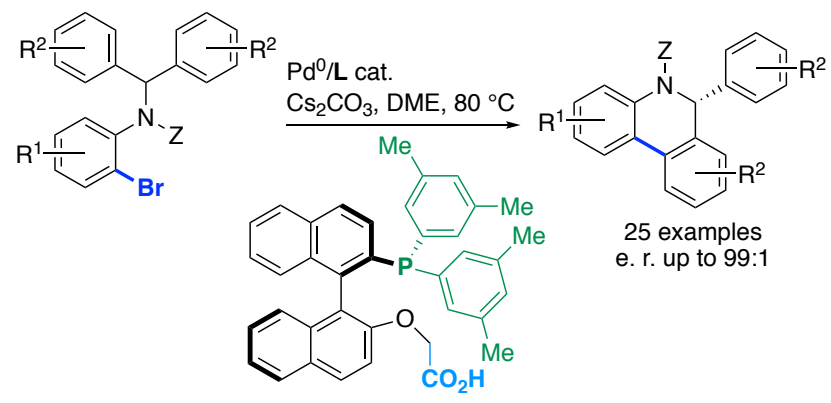

Chiral chimera: Bifunctional ligands incorporating both a phosphine and a carboxylate moiety provide high enantioselectivities in the synthesis of 5,6dihydrophenanthridines, whereas the corresponding bimolecular systems are poorly stereoselective. 